\title{
Relationship Between Nutritional Status and Quality of Life in Patients with Lung Cancer
}

This article was published in the following Dove Press journal: Cancer Management and Research

\author{
Jacek Polański' \\ Beata Jankowska-Polańska ${ }^{2}$ \\ Grzegorz Mazur (D) \\ 'Department of Internal Medicine, \\ Occupational Diseases, Hypertension and \\ Clinical Oncology, Wrocław Medical \\ University, Wrocław, 50-367, Poland; \\ ${ }^{2}$ Department of Clinical Nursing, \\ Wrocław Medical University, Wrocław, \\ 50-367, Poland
}

Introduction: Malnutrition is often co-occur in patients with advanced cancer and are associated with poorer response to treatment therapy and decrease significantly the quality of life (QoL). There is little evidence regarding the relationship between nutritional status and QoL in this patient group.

Purpose of the Study: To assess the relationship between nutritional status and QoL in patients with lung cancer.

Methods: Our cross-sectional, descriptive study included 310 patients. Only standardized instruments were used to perform the study: Mini Nutritional Assessment (MNA) to assess nutritional status and The European Organization for Research and Treatment of Cancer Quality of Life Core-30 (EORTC-QLQ-C30) and Lung Cancer-13 (LC-13) to assess the QoL.

Results: The mean age in the study group was $63.77 \pm 9.43 .18 .71 \%$ of patients were malnourished $44.19 \%$ at risk of malnutrition and $37.1 \%$ of patients had normal nutritional status. Clinical characteristics showed that $75 \%$ of respondents had been diagnosed with nonsmall-cell lung carcinoma, with an average duration of illness of 1-2 years. Nearly all patients received symptomatic treatment, and one in two had undergone surgery. At subsequent stages, QoL was analyzed in three groups depending on nutritional status risk. Malnourished patients had a lower quality of life and greater severity of cancer symptoms than those with a normal nutritional status $(\mathrm{p}<0.001)$. In regression analysis, nutritional status has a significant impact on all QLQ-C30 functional scales. Regression parameters are positive, indicating that better nutritional status is associated with better functioning in specific QLQ domains.

Conclusion: A considerable proportion of lung cancer patients are either malnourished or at risk of malnutrition. Malnutrition correlates negatively with QoL and increases symptom severity. Malnutrition is an independent determinant of lower QoL.

Implications for Practice: Nutritional assessment should be accompanied by QoL evaluation, so that nutritional interventions can be optimized based on a patient's individual requirements.

Keywords: malnutrition, lung cancer, quality of life

\section{Introduction}

Lung cancer is the most common malignancy in Poland and worldwide. ${ }^{1,2}$ According to the published data, lung cancer accounts for approx. 14\% of all new cancer cases in Poland. ${ }^{1}$ It is worth noting that it also accounts for approx. One-third of all cancer deaths. Lung cancer remains the leading cause of cancer morbidity and mortality worldwide, representing nearly $18.4 \%$ of cancer deaths. ${ }^{2}$ Prognosis in lung cancer mainly depends on the cancer stage at diagnosis; in
Correspondence: Beata JankowskaPolańska

Department of Clinical Nursing, Wrocław Medical University, UI. Ludwika Pasteura I, Wrocław, 50-367, Poland

Tel +48793477007

Email beata.jankowska-polanska@umed. wroc.pl
Cancer Management and Research 2021:13 1407-1416 
advanced lung cancers, significant prognostic factors include performance status and weight loss before diagnosis. ${ }^{3}$ Despite major advances in oncology, lung cancer treatment does not yet produce satisfactory outcomes, which is most commonly due to late diagnosis, elderly patient age, and comorbidities that restrict the available therapeutic options. ${ }^{1}$

The most common symptoms of local tumor growth include coughing, dyspnea, hemoptysis and pain. Indicators of regional tumor growth include dysphagia, dyspnea, hoarseness, Horner's syndrome, hypoxia, Pancoast syndrome, pericardial or pleural effusion, and superior vena cava syndrome. ${ }^{4}$ Symptoms indicative of metastasis include headaches, enlarged liver, psychological changes, pain, fainting, weakness and cachexia.

Cancer anorexia-cachexia syndrome (CACS) affects $55-85 \%$ of patients with advanced cancers. Malnutrition is found in $30-85 \%$ patients with lung cancer and indicates a poorer prognosis. CACS is associated with increased skeletal muscle protein catabolism, loss of muscle mass and body weight, and malnutrition. Cachexia and CACS have been associated with poor prognosis, increased frequency of hospitalization, and a very high mortality risk.

Rapidly progressing cachexia leads to anemia, nutritional deficiencies, loss of muscle mass, activity restriction, internal organ and immune system dysfunction, changes in outward appearance, depression, weakening of social ties, quality of life (QoL) deterioration, and ultimately-shorter survival. ${ }^{5}$ Poor nutritional status also seems to be associated with disease severity and progression $^{6}$ and with the treatment used. QoL assessment has recently been widely adopted in clinical practice to support decision-making with regard to patient treatment and care. ${ }^{7-10}$

Nutritional status evaluation, followed by appropriate nutritional intervention, allows patients to better manage potential adverse events associated with their disease, ultimately improving their QoL. ${ }^{11}$ Despite the broad recognition of its importance, few studies so far have looked at nutritional status in cancer patients in the context of its impact on QoL.

In cancer patients, QoL is significantly affected by the specific diagnosis, its meaning for the patient, the disease's impact on the patient's physical and mental condition, short- and long-term adverse effects of treatment, the patient's coping mechanisms, and the reactions of their family members or other individuals. ${ }^{12}$ Both the cancer itself and its treatment entail considerable biochemical and psychological changes, all of which may affect the patient's QoL. ${ }^{13}$

There is little evidence regarding the relationship between nutritional status and QoL, anxiety, and depression in this patient group, ${ }^{14,15}$ as well as that between nutritional status and survival. Despite the broad recognition of its importance, few studies so far have looked at nutritional status in cancer patients in the context of its impact on QoL. With the above considerations in mind, we have designed and performed the present study to investigate any associations between nutritional status and QoL in lung cancer patients.

The purpose of the study was to assess the relationship between nutritional status (Mini Nutritional Assessment MNA) and QoL (The European Organization for Research and Treatment of Cancer Quality of Life Core-30: EORTC-QLQ-C30 and Lung Cancer-13: LC-13) in patients with lung cancer.

\section{Patients and Methods}

Our cross-sectional, descriptive study included 310 patients, aged 18 or above, treated at the Lung Center, between March 2019 and June 2020.

Exclusion criteria were: age below 18 years; uncertain diagnosis of neoplasm; lack of the consent for participation in the study; serious chronic co-morbidities which may interfere the perception of one's own health situation (other malignant neoplasm, heart failure in exacerbation phase, severe COPD, asthmatic state, state of hemodynamic instability); cognitive dysfunction indicative of dementia.

A total of 358 patients were invited into the study, then 35 patients resigned, and 13 questionnaires were filled out improperly. All patients included in the study in accordance with the set criteria were administered a survey, and their socio-demographic and clinical data were obtained from the available medical records.

Comparative analysis of the quality of life QoL was conducted Analyzed in three groups of patients, depending on nutritional status: group 1 Malnutrition $(\mathrm{N}=58)$ group 2: Risk of malnutrition $(\mathrm{N}=137)$ group 3: Normal nutritional status $(\mathrm{N}=115)$

All patients included were informed about the purpose and course of the study and advised that they could withdraw from it at any time. All the patients included provided their written informed consent to participate in the survey. As a general rule, questionnaires were completed by the patients without assistance, but with the researcher 
present. In case of difficulties with questionnaire completion, a patient could use the researcher's help, but even in that case, all responses were solely their own. The study had been approved by the Ethics Committee of the Wroclaw Medical University (No 729/2019). The study protocol was carried out in accordance with the tenets of the Declaration of Helsinki and Good Clinical Practice guidelines.

Only standardized instruments listed and described below were used to perform the study.

The EORTC QLQ-C30 quality of life questionnaire with the QLQ-LC13 lung cancer module is a standardized instrument (version 3.0) dedicated to cancer patients. It is among the most commonly used scales in cancer research, with high validity, reliability, and accuracy. ${ }^{16,17}$ The QLQ-C30 allows for a comprehensive analysis of a patient's perceived health and functioning in the physical, emotional, and social dimension. It comprises 30 items related to five areas of functioning (physical, cognitive, emotional, social, role), nine symptoms (fatigue, pain, nausea and vomiting, dyspnea, insomnia, appetite loss, constipation, diarrhea, financial difficulties), and general health. Scores reflect the patient's QoL. It is among the most commonly used scales in cancer research, with high validity, reliability, and accuracy. Raw scores for each item are converted into a standard 0-100 scale. Higher scores in general health and function items indicate better QoL, while higher scores for symptoms indicate poorer QoL. Our use of the questionnaire was approved by the Quality of Life Group within the EORTC (The European Organisation for Research and Treatment of Cancer) seated in Brussels.

\section{Mini Nutritional Assessment (MNA) Questionnaire}

All patients were tested using the complete $\mathrm{MNA}^{\circledR}$ Mini Nutritional Assessment questionnaire (Nestlé Nutrition Institute), comprising the screening part and the assessment part. The screening part comprises six items: food intake, anthropometric parameters, and general parameters (mobility, physical and emotional stress, neuropsychological parameters). The assessment part comprises 12 items: anthropometric parameters (calf and upper arm circumference), general characteristics (six items regarding lifestyle, medication, and mobility), diet (number of meals, food and fluid intake, mode of feeding), and subjective assessment (self-reported health and nutritional status). The arm circumference was measured on the left limb lowered freely along the body at its widest point. Calf circumference was measured in a sitting position at the widest point of the calf using an anthropometric tape. Total MNA scores from both parts are used to identify patients with a normal nutritional status ( $\geq 24$ points), at risk of malnutrition (17-23 points), and with protein-calorie malnutrition ( $<17$ points). Validation studies have demonstrated the high reliability and validity of this instrument (scale sensitivity—97.9\%, scale specificity—100\%). ${ }^{18}$

\section{ECOG Performance Status}

This is one of the most frequently used scales for assessing the state of fitness of patients with cancer. This scale consists of six degrees, from 0 to 5 , where 0 determines the state of full activity, without symptoms of the disease, and grade 5 is death. ${ }^{19}$

A questionnaire comprising items related to patients' demographic characteristics, smoking and alcohol intake was completed by researchers based on individual interviews. Data on the disease (type and stage, time from diagnosis, treatment received) were collected from the patients' medical records.

\section{Statistical Analysis}

The data were statistically analyzed. Descriptive statistics were calculated. The compliance of the distributions of the examined parameters with the normal distribution was verified with the chi-square test. Data are presented as the mean $\pm \mathrm{SD}$ for continuous variables and number (percentage) for categorical variables. Inter-group differences were assessed by ANOVA and post hoc test (Tukey honest significant difference). Statistical analysis was carried out with STATISTICA v.13.3 software (TIBCO Software Inc.).

\section{Results}

\section{Patients' Socio-Demographic Characteristics}

The mean age in the study group was $63.8 \pm 9.4$ years. A slight majority of patients was male (57.1\%) and in a relationship (56.1\%). Nearly $69 \%$ of respondents lived in cities, and a decisive majority was professionally inactive ( $72 \%$-retirees/pensioners). Most patients reported vocational $(44.1 \%)$ or high school education $(33.2 \%)$. (Table 1) 
Table I Patients' Socio-Demographic Characteristics - Whole Group of Patients with Lung Cancer

\begin{tabular}{|c|c|c|}
\hline \multicolumn{2}{|l|}{ Parameters } & \multirow{2}{*}{$\frac{\text { All }(n=310)}{63.8 \pm 9.4}$} \\
\hline Age [years] & Mean \pm SD & \\
\hline Sex & $\begin{array}{l}\text { Female } \\
\text { Male }\end{array}$ & $\begin{array}{l}133(42.9 \%) \\
177(57.1 \%)\end{array}$ \\
\hline Residence & $\begin{array}{l}\text { Urban } \\
\text { Rural }\end{array}$ & $\begin{array}{l}215 \text { (69.4\%) } \\
95(30.6 \%)\end{array}$ \\
\hline Source of income & $\begin{array}{l}\text { Professional activity } \\
\text { Social welfare, disability pension, retirement, family support }\end{array}$ & $\begin{array}{l}86(27.7 \%) \\
224(72.3 \%)\end{array}$ \\
\hline Relationship status & $\begin{array}{l}\text { In a relationship } \\
\text { Single }\end{array}$ & $\begin{array}{l}174(56.1 \%) \\
136(43.9 \%)\end{array}$ \\
\hline Education & $\begin{array}{l}\text { Primary } \\
\text { Vocational } \\
\text { High school } \\
\text { College/university }\end{array}$ & $\begin{array}{l}34(11.0 \%) \\
137(44.2 \%) \\
103(33.2 \%) \\
36(11.6 \%)\end{array}$ \\
\hline
\end{tabular}

Clinical characteristics showed that $75 \%$ of respondents had been diagnosed with non-small-cell lung carcinoma, with an average duration of illness of 1-2 years. The most common staging parameters were $\mathrm{T} 4$ (38.06\%), N2 (32.29\%), and M0 (57.1\%). More than half of the respondents were free from distant metastases. Where such metastases existed, they were located in the liver $(13.8 \%)$ and adrenal glands (11.3\%). The number of hospitalizations in the study group was $1.35 \pm 1.99$. Nearly all patients received symptomatic treatment, and one in two had undergone surgery. The most common complaints included chronic coughing (nearly $83 \%$ ), dyspnea $(68.71 \%)$, and chest pain $(68.71 \%)$. The patients in our group were assigned grade $1(41.5 \%)$ or 2 on the Zubrod performance scale. Body weight analysis showed that less than $40 \%$ of respondents had normal body weight (37.1\%), 44.2\% were at risk of malnutrition, and $18.8 \%$ were malnourished to an extent requiring intervention. Additionally, spirometry results were analyzed. FEV1 was $2.47 \pm 3.52$ for the entire group, FVC was $3.51 \pm 4.91$, and FEV1/FVC [\%] was 67.99 \pm 14.03 . (Table 2)

\section{Quality of Life Scores}

At subsequent stages, QoL was analyzed in three groups, depending on nutritional status.

An analysis of QoL as measured by EORTC-QLQ domains, considering nutritional status, demonstrated that overall QoL, physical functioning, role functioning, and cognitive functioning were better in patients with a better nutritional status.

- Emotional and social functioning was significantly better in the group with a normal nutritional status than in the two remaining groups.

- Fatigue, nausea and vomiting, pain, dyspnea, appetite loss, coughing, mouth or tongue pain, difficulty swallowing, and hair loss were more severe in patients with poorer nutritional status.

- Insomnia, diarrhea, financial difficulties, shortness of breath, tingling in the hands or feet, chest pain, arm or shoulder pain, pain in other body parts, and ineffectiveness of pain medication were significantly less severe in the group with a normal nutritional status than in the other two groups. Constipation and hemoptysis were significantly more severe in the malnourished group than in the two remaining groups. The results are shown in Table 3.

\section{Regression Analysis for the Impact of Nutritional Status on QoL}

Nutritional status has a significant and positive impact on all QLQ-C30 functional scales, both in single- and multiple-factor analyses. Regression parameters are positive, indicating that better nutritional status is associated with better functioning in specific QLQ domains.

As expected, the impact of MNA scores on the QLQ-C30 and QLQ-LC13 symptom scales is negative, 
Table 2 Participants' Clinical Characteristics - Whole Group of Patients with Lung Cancer

\begin{tabular}{|c|c|c|}
\hline Parameter & & All $(n=3 \mid 0)$ \\
\hline Year of diagnosis & $\begin{array}{l}4 \text { and more } \\
3 \\
2 \\
1\end{array}$ & $\begin{array}{l}24(7.7 \%) \\
16(5.2 \%) \\
233(75.2 \%) \\
37(11.9 \%)\end{array}$ \\
\hline Cancer type & $\begin{array}{l}\text { Small-cell } \\
\text { carcinoma } \\
\text { Non-small-cell } \\
\text { carcinoma }\end{array}$ & $\begin{array}{l}76(24.5 \%) \\
234(75.5 \%)\end{array}$ \\
\hline $\mathbf{T}$ parameter & $\begin{array}{l}\text { TI } \\
\text { T2 } \\
\text { T3 } \\
\text { T4 } \\
\text { Tx } \\
\text { No data }\end{array}$ & $\begin{array}{l}51(16.5 \%) \\
99(31.9 \%) \\
37(11.9 \%) \\
118(38.1 \%) \\
2(0.6 \%) \\
3(1.0 \%)\end{array}$ \\
\hline $\mathbf{N}$ parameter & $\begin{array}{l}\text { No } \\
\text { NI } \\
\text { N2 } \\
\text { N3 } \\
\text { Nx } \\
\text { No data }\end{array}$ & $\begin{array}{l}96(30.97 \%) \\
60(19.35 \%) \\
97(31.29 \%) \\
30(9.68 \%) \\
24(7.74 \%) \\
3(0.97 \%)\end{array}$ \\
\hline M parameter & $\begin{array}{l}\text { Mo } \\
\text { Mla } \\
\text { MIb, Mlc } \\
\text { Mx } \\
\text { No data }\end{array}$ & $\begin{array}{l}177(57.10 \%) \\
84(27.10 \%) \\
8(2.58 \%) \\
38(12.26 \%) \\
3(0.97 \%)\end{array}$ \\
\hline $\begin{array}{l}\text { Metastases to: } \\
\text { bone } \\
\text { brain } \\
\text { liver } \\
\text { adrenal glands } \\
\text { multiple organs } \\
\text { no metastasis }\end{array}$ & Yes & $\begin{array}{l}24(7.74 \%) \\
24(7.74 \%) \\
43(13.87 \%) \\
35(11.29 \%) \\
28(9.03 \%) \\
181(58.39 \%)\end{array}$ \\
\hline Number of hospitalizations & mean $\pm S D$ & $1.35 \pm 1.99$ \\
\hline $\begin{array}{l}\text { Type of treatment } \\
\text { Surgical treatment } \\
\text { Chemotherapy } \\
\text { Radiotherapy } \\
\text { Symptomatic treatment } \\
\text { Unconventional treatment }\end{array}$ & Yes & $\begin{array}{l}152(49.03 \%) \\
118(38.06 \%) \\
105(33.87 \%) \\
209(67.42 \%) \\
8(2.58 \%) \text { (more than one } \\
\text { answer was possible) }\end{array}$ \\
\hline $\begin{array}{l}\text { Symptoms } \\
\text { Chronic coughing } \\
\text { Dyspnea } \\
\text { Chest pain } \\
\text { Hemoptysis } \\
\text { Recurrent infections } \\
\text { Cardiac arrhythmia } \\
\text { Hoarseness }\end{array}$ & Yes & $\begin{array}{l}254(81.94 \%) \\
213(68.71 \%) \\
213(68.71 \%) \\
88(28.39 \%) \\
83(26.77 \%) \\
40(12.90 \%) \\
68(21.94 \%)\end{array}$ \\
\hline
\end{tabular}

(Continued)
Table 2 (Continued).

\begin{tabular}{|c|c|c|}
\hline Parameter & & All $(n=3 \mid 0)$ \\
\hline Performance status & $\begin{array}{l}0 \\
1 \\
2 \\
3 \text { or } 4\end{array}$ & $\begin{array}{l}50(16.13 \%) \\
129(41.61 \%) \\
105(33.87 \%) \\
26(8.39 \%)\end{array}$ \\
\hline FEVI [L] & mean $\pm S D$ & $2.47 \pm 3.52$ \\
\hline FVC [L] & mean $\pm S D$ & $3.51 \pm 4.91$ \\
\hline FEVI/FVC [\%] & mean $\pm S D$ & $67.99 \pm 14.03$ \\
\hline BMI & $\mathrm{Kg} / \mathrm{m}^{2}$ & $22.3(20.1-24.4)$ \\
\hline MNA & & \\
\hline Malnourished & 58 & $18.71 \%$ \\
\hline At risk of malnutrition & 137 & $44.19 \%$ \\
\hline Normal nutritional status & 115 & $37.10 \%$ \\
\hline
\end{tabular}

both in single and multiple-factor analyses. Negative regression parameters indicate that better nutritional status is associated with less severe symptoms and less impact on QoL.

In multiple-factor analyses, the impact was weaker, as regression parameter values were closer to zero than in single-factor analyses. Therefore, variables from Table 1, used to correct the multiple-factor analysis, partially "account" for the impact of nutritional status on QoL. The only exception is arm and shoulder pain, which did not depend on MNA in multiple-factor analysis (Table 4)

In summary, QoL in all EORTC-QLQ domains is dependent on nutritional status. However, this impact is partially accounted for by other socio-demographic and clinical variables. After adjusting for their confounding effects, the impact of nutritional status weakens, but remains significant (except for the arm and shoulder pain domain). Nutritional status may thus be considered a significant and independent predictor on QoL in all the domains studied except one. The results are shown in Table 4.

\section{Discussion}

A considerable proportion of lung cancer patients are either malnourished or at risk of malnutrition. QoL in cancer patients depends on cancer type, its location, stage, the treatment used, and prognosis. As reported by the authors of the available publications on this subject, QoL in lung cancer patients is considerably poorer than in the healthy population. ${ }^{20,21}$ Malnutrition is a negative prognostic factor in advanced lung cancer, linked to poorer 
Table 3 EORTC-QLQ Scores in Patients with Lung Cancer Depending on Nutritional Status

\begin{tabular}{|c|c|c|c|c|}
\hline \multirow[t]{2}{*}{ QLQ } & \multicolumn{3}{|l|}{ MNA } & \multirow[t]{2}{*}{$\mathbf{p}$} \\
\hline & $\begin{array}{l}\text { Malnutrition } \\
(\mathrm{N}=58)\end{array}$ & $\begin{array}{l}\text { Risk of Malnutrition } \\
(\mathrm{N}=137)\end{array}$ & $\begin{array}{l}\text { Normal Nutritional Status } \\
(\mathrm{N}=|| 15)\end{array}$ & \\
\hline & \multicolumn{3}{|l|}{$($ mean $\pm S D)$} & \\
\hline Overall quality of life & $28.16 \pm 17.92$ & $35.64 \pm 17.29$ & $55.14 \pm 23.48$ & $p<0.00$ I* \\
\hline Physical functioning & $47.13 \pm 21.3$ & $64.77 \pm 17.79$ & $79.3 \pm 14.14$ & $\mathrm{p}<0.00$ I* \\
\hline Role functioning & $36.21 \pm 25.96$ & $49.64 \pm 26.23$ & $76.38 \pm 25.55$ & $\mathrm{P}<0.00$ I* \\
\hline Emotional functioning & $43.97 \pm 25.3$ & $43.43 \pm 22.79$ & $65.65 \pm 32.05$ & $\mathrm{P}<0.001 *$ \\
\hline Cognitive functioning & $56.61 \pm 23.14$ & $64.84 \pm 20.78$ & $84.2 \pm 19.1$ & $\mathrm{P}<0.00 \mathrm{I}^{*}$ \\
\hline Social functioning & $50.86 \pm 28.51$ & $47.81 \pm 29.48$ & $72.9 \pm 32.03$ & $\mathrm{p}<0.00 \mathrm{I}^{*}$ \\
\hline Fatigue & $65.9 \pm 22.01$ & $56.45 \pm 23.76$ & $31.88 \pm 23.53$ & $\mathrm{P}<0.00$ I* \\
\hline Nausea and vomiting & $35.63 \pm 27.12$ & $21.53 \pm 21.21$ & $8.26 \pm 14.87$ & $\mathrm{P}<0.00$ I* \\
\hline Pain & $58.91 \pm 22.99$ & $46.96 \pm 22.25$ & $27.39 \pm 22.21$ & $\mathrm{p}<0.00$ I* \\
\hline Dyspnea & $62.64 \pm 24.25$ & $50.36 \pm 24.63$ & $35.36 \pm 23.06$ & $\mathrm{p}<0.00$ I* \\
\hline Insomnia & $63.79 \pm 21.88$ & $57.66 \pm 27.27$ & $31.59 \pm 33.58$ & $\mathrm{p}=0.00 \mathrm{I} *$ \\
\hline Appetite loss & $58.05 \pm 26.17$ & $41.61 \pm 27.65$ & $22.9 \pm 26.99$ & $\mathrm{p}=0.00 \mathrm{I} *$ \\
\hline Constipation & $39.66 \pm 32.12$ & $17.27 \pm 24.62$ & $15.36 \pm 23.48$ & $\mathrm{p}=0.00 \mathrm{I} *$ \\
\hline Diarrhea & $13.22 \pm 22.46$ & $13.38 \pm 25.07$ & $4.35 \pm 16.24$ & $\mathrm{p}=0.00 \mathrm{I} *$ \\
\hline Financial difficulties & $56.32 \pm 30.72$ & $50.85 \pm 28.89$ & $27.25 \pm 32.62$ & $\mathrm{p}=0.00 \mathrm{I} *$ \\
\hline Shortness of breath & $53.45 \pm 22.36$ & $46.07 \pm 21.07$ & $25.02 \pm 18.66$ & $\mathrm{p}=0.00 \mathrm{I} *$ \\
\hline Coughing & $64.94 \pm 22.88$ & $55.72 \pm 23.26$ & $41.81 \pm 22.09$ & $\mathrm{p}=0.00 \mathrm{I} *$ \\
\hline Hemoptysis & $27.01 \pm 30.24$ & $14.1 \mid \pm 20.1$ & $11.59 \pm 17.68$ & $\mathrm{p}=0.003 *$ \\
\hline Sore mouth or tongue & $27.01 \pm 28.92$ & $|3.87 \pm| 8.8 \mid$ & $5.5 I \pm \mid 4.6$ & $\mathrm{p}=0.00 \mathrm{I} *$ \\
\hline Difficulty swallowing & $35.63 \pm 29.19$ & $16.79 \pm 19.85$ & $6.67 \pm 14.78$ & $\mathrm{p}=0.00 \mathrm{I} *$ \\
\hline Tingling in hands or feet & $24.7 I \pm 30.3 I$ & $20.68 \pm 21.06$ & $9.57 \pm 16.38$ & $\mathrm{p}=0.00 \mathrm{I} *$ \\
\hline Hair loss & $35.63 \pm 35.79$ & $|9.46 \pm 27.6|$ & $9.57 \pm 22.41$ & $\mathrm{p}=0.00 \mathrm{I} *$ \\
\hline Chest pain & $45.4 \pm 32.26$ & $34.31 \pm 25.55$ & $17.97 \pm 22.2$ & $\mathrm{P}=0.00 \mathrm{I} *$ \\
\hline Arm or shoulder pain & $23.56 \pm 31.22$ & $16.06 \pm 22.9$ & $10.14 \pm 21.25$ & $\mathrm{p}=0.003 *$ \\
\hline Pain in other body parts & $40.8 \pm 36.43$ & $30.9 \pm 26.39$ & $12.75 \pm 22.33$ & $\mathrm{p}<0.00$ I* \\
\hline $\begin{array}{l}\text { No improvement with pain } \\
\text { medication }\end{array}$ & $61.06 \pm 17.44$ & $58.26 \pm 16.68$ & $45.97 \pm 17.05$ & $\mathrm{p}=0.00 \mathrm{I}^{*}$ \\
\hline
\end{tabular}

Notes: ANOVA + post hoc analysis (Tukey HSD). *Statistically significant $(p<0.05)$.

outcomes, lower treatment tolerance, shorter survival, 22 lower treatment effectiveness, ${ }^{22}$ and a higher cost of care. ${ }^{3}$ Studies published to date indicate that eating disorders, cachexia, and sarcopenia are often undiagnosed and untreated or treated ineffectively. ${ }^{15}$ Our results indicate that nearly half of the patients in the study group were at risk of malnutrition, and almost $20 \%$ were classified as malnourished. Published estimates place the prevalence of malnutrition among patients with lung cancer at between $35 \%$ and $68 \% .^{14-16}$ It is believed that many patients are already malnourished at the time of their first oncologist visit, $^{23}$ and malnutrition may grow more severe over time or after chemotherapy. Malnutrition is particularly common in hospitalized patients and in those with advanced, metastatic disease. ${ }^{24-26}$
According to the National Cancer Institute's Nutrition in Cancer Care guidelines, timely identification and treatment of nutritional problems may improve prognosis in cancer patients, helping them gain or maintain body weight, improving their response to treatment, and reducing complications from therapy. In a European study, median weight loss was $6.5 \%$, while $34.5 \%$ of patients reported weight loss exceeding $10 \%$ before treatment. ${ }^{27}$

In our study, most patients had been treated for lung cancer for about one year, and the number of hospitalizations in that period was 1.4 . Treatment was most commonly symptomatic, and one in two patients had undergone surgery. These therapeutic interventions have an adverse impact on body weight, but at the same time, weight loss may inhibit response to treatment. As shown by published studies, 31\% 
Table 4 Regression Analysis for the Impact of Nutritional Status on EORTC-QLQ Domains

\begin{tabular}{|c|c|c|c|c|c|c|c|c|c|}
\hline \multirow{8}{*}{$\begin{array}{l}\text { Questionnaire } \\
\text { QLQ-C30 - functional } \\
\text { scales }\end{array}$} & \multirow{3}{*}{$\begin{array}{l}\text { Subscale } \\
\text { Overall quality of life }\end{array}$} & \multicolumn{4}{|c|}{ Univariate } & \multicolumn{4}{|c|}{ Multivariate } \\
\hline & & \multirow{2}{*}{$\begin{array}{l}\text { b } \\
2.21\end{array}$} & \multicolumn{2}{|l|}{$95 \% \mathrm{Cl}$} & \multirow{2}{*}{$\begin{array}{l}\mathbf{p} \\
<0.00 I^{*}\end{array}$} & \multirow{2}{*}{$\begin{array}{l}\text { b } \\
1.365\end{array}$} & \multicolumn{2}{|l|}{$95 \% \mathrm{Cl}$} & \multirow{2}{*}{$\begin{array}{l}\mathbf{p} \\
<0.00 I^{*}\end{array}$} \\
\hline & & & $\mathrm{I} .777$ & 2.643 & & & 0.882 & 1.849 & \\
\hline & Physical functioning & 2.463 & 2.098 & 2.827 & $<0.00 I^{*}$ & 1.682 & 1.301 & 2.063 & $<0.001 *$ \\
\hline & Role functioning & 3.114 & 2.547 & 3.682 & $<0.00 I^{*}$ & 1.744 & 1.163 & 2.326 & $<0.001 *$ \\
\hline & Emotional functioning & 2.131 & 1.539 & 2.724 & $<0.00 I^{*}$ & 1.473 & 0.852 & 2.094 & $<0.001 *$ \\
\hline & Cognitive functioning & 2.392 & 1.953 & 2.831 & $<0.00 I^{*}$ & 1.843 & 1.346 & 2.34 & $<0.001 *$ \\
\hline & Social functioning & 2.142 & 1.47 & 2.814 & $<0.00 I^{*}$ & 0.915 & 0.23 & 1.6 & $0.009 *$ \\
\hline \multirow{9}{*}{$\begin{array}{l}\text { QLQ-C30 - symptom } \\
\text { scales }\end{array}$} & Fatigue & -2.894 & -3.393 & -2.394 & $<0.001 *$ & -1.982 & -2.527 & -1.437 & $<0.001 *$ \\
\hline & Nausea and vomiting & -2.126 & -2.565 & -1.688 & $<0.00 I^{*}$ & -1.652 & -2.153 & $-1.15 \mid$ & $<0.001 *$ \\
\hline & Pain & -2.483 & -2.967 & -1.999 & $<0.00 I^{*}$ & -1.827 & -2.356 & -1.297 & $<0.001 *$ \\
\hline & Dyspnea & -2.221 & -2.735 & -1.706 & $<0.00 I^{*}$ & -1.477 & -2.056 & -0.898 & $<0.001 *$ \\
\hline & Insomnia & -2.725 & -3.359 & -2.091 & $<0.00 I^{*}$ & -1.929 & -2.631 & -1.227 & $<0.001 *$ \\
\hline & Appetite loss & -2.957 & -3.528 & -2.385 & $<0.00 I^{*}$ & -2.47 & -3.189 & $-1.75 \mid$ & $<0.001 *$ \\
\hline & Constipation & -1.626 & -2.198 & -1.053 & $<0.00 I^{*}$ & -1.263 & -1.975 & -0.552 & $0.001 *$ \\
\hline & Diarrhea & -0.911 & -1.385 & -0.436 & $<0.001 *$ & -0.655 & $-1.26 \mid$ & -0.048 & $0.036 *$ \\
\hline & Financial difficulties & -2.586 & -3.252 & -1.92 & $<0.00 I^{*}$ & -1.074 & -1.8 & -0.348 & $0.004 *$ \\
\hline \multirow[t]{11}{*}{ QLQ-LCI3 } & Shortness of breath & -2.421 & -2.862 & -1.981 & $<0.00 I^{*}$ & -1.672 & -2.184 & $-1.16 \mid$ & $<0.001 *$ \\
\hline & Coughing & -1.878 & -2.372 & -1.385 & $<0.00 I^{*}$ & -1.832 & -2.423 & $-|.24|$ & $<0.001 *$ \\
\hline & Hemoptysis & -1.112 & -1.585 & -0.639 & $<0.00 I^{*}$ & -0.913 & -1.363 & -0.463 & $<0.001 *$ \\
\hline & Sore mouth or tongue & -1.725 & -2.149 & -1.302 & $<0.00 I^{*}$ & -0.947 & -1.459 & -0.434 & $<0.001 *$ \\
\hline & Difficulty swallowing & -2.204 & -2.639 & -1.768 & $<0.00 I^{*}$ & -1.679 & -2.216 & -1.143 & $<0.001 *$ \\
\hline & Tingling in hands or feet & -1.506 & -1.97 & -1.043 & $<0.00$ I* & -0.86 & -1.396 & -0.325 & $0.002 *$ \\
\hline & Hair loss & -1.943 & -2.545 & -1.342 & $<0.001 *$ & -1.059 & $-1.7 \mid$ & -0.409 & $0.002 *$ \\
\hline & Chest pain & -2.131 & -2.693 & -1.569 & $<0.00 I^{*}$ & -1.329 & -1.968 & -0.69 & $<0.001 *$ \\
\hline & Arm or shoulder pain & -1.033 & -1.561 & -0.506 & $<0.00 I^{*}$ & -0.597 & -1.224 & 0.029 & 0.063 \\
\hline & Pain in other body parts & -2.416 & -2.999 & -1.832 & $<0.00 I^{*}$ & -2.13 & -2.886 & -1.374 & $<0.001 *$ \\
\hline & $\begin{array}{l}\text { No improvement with pain } \\
\text { medication }\end{array}$ & -1.114 & -1.558 & -0.67 & $<0.001 *$ & -1.143 & -1.678 & -0.609 & $<0.001 *$ \\
\hline
\end{tabular}

Notes: *Statistically significant $(\mathrm{p}<0.05)$, b - linear regression coefficient, impact of nutritional status on domains and areas of quality of life.

of patients experience persistent weight loss due to tumor growth and radiotherapy. ${ }^{28}$ Both cancer and cancer treatments affect patients' nutritional status due to lower food intake and altered metabolism. Poor nutritional status is a prognostic factor in non-small cell lung cancer. ${ }^{29}$

Self-reported QoL is based on a subjective scale representing symptom severity. It complements clinical evaluation and can be used to support predictions regarding survival. ${ }^{15}$ Additionally, in lung cancer patients, a higher pain threshold has been demonstrated to correlate with poorer nutritional status, as poor nutrition is often caused by an impaired ability to take in food due to a higher pain threshold. $^{30}$

Some authors strongly emphasize the importance of nutritional status in the daily functioning of patients with cancer, not only lung cancer. Weight loss is correlated with lower survival, and is a strong negative prognostic factor.
In our study, QoL was significantly lower in groups with an unsatisfactory nutritional status, ie among patients who were at risk of malnutrition or were malnourished. In regression analysis, a normal nutritional status had a significant positive impact on all the functional scales of the EORTC questionnaire, and a significant negative impact on its symptom scales, meaning that it was associated with a better QoL and lower symptom severity.

Self-reported QoL is a significant measure of treatment outcomes in cancer patients. Physical and mental performance, including nutritional status, determine patients' attitudes towards the disease and their strength in coping with it. The available publications demonstrate that problems, including nutritional ones, increase in severity along with the duration and stage of lung cancer. Patients' well-being has a major impact on their daily functioning and ability to perform social and professional 
roles. The literature reports that patients with lung cancer experience severe pain, dyspnea, and anxiety and depression, and most of their symptoms are negatively correlated with perceived QoL. ${ }^{15}$ In our study, patients who were at risk of malnutrition or malnourished had more severe symptoms, including: coughing, shortness of breath, and chest pain, as well as more financial difficulties, compared to those with a normal nutritional status. In the study by Gupta et al, as in the present one, well-nourished patients obtained higher QoL scores than those with a poorer nutritional status. ${ }^{8}$ Mohan et al (2008) found that anorexia is among the most common symptoms, and is present in as many as $57 \%$ of stage III and IV lung cancer patients. ${ }^{31}$ Some patients not responding to chemotherapy experience fever, anorexia, and weight loss from the start of treatment. Some authors believe that chemotherapy does not significantly improve respiratory function or nutritional status, and thus has no positive impact on QoL. In our study, as many as $86 \%$ of patients received chemotherapy, and more than $30 \%$ underwent lung resection, while published reports indicate that some forms of treatment can actually only exacerbate functional disorders and reduce QoL. In our study, one in two patients had undergone surgery, and all patients received symptomatic treatment. This might indicate that firstly, some patients had more positive emotions related to the treatment and a belief in its effectiveness, and secondly, patients who are not treated with chemotherapy do not experience the distressing adverse effects of the treatment.

The study by Payne et $\mathrm{al}^{32}$ suggests a possibility that interventions to improve patients' nutritional status may bring benefits in terms of physical strength and functional capacity. However, all interventions should be undertaken with a large degree of caution due to the lack of evidence on the subject.

The studies that are available emphasize the importance of abnormal weight loss as a determinant of functional limitations and loss of independence. As reported by Ovesen, ${ }^{33}$ weight loss was associated with restrictions in activity and a lower global health assessment scores in patients with lung, breast, and ovarian cancer. In studies by other authors, weight loss was linked to lower QoL and greater severity of symptoms, particularly pain and fatigue, in the EORTC QLQ-C30. ${ }^{34}$ In summary, it should be emphasized that malnutrition is a statistically significant independent determinant of QoL, though alongside nutritional status, QoL is also significantly affected by other symptoms related to nutrition, nausea and vomiting, appetite loss, diarrhea, and constipation, as well as pain, age, duration of disease, and the treatment used. ${ }^{35-37}$ Some authors have shown that more severe symptoms are correlated with a lower QoL, and the most significant impact was observed for appetite loss, fatigue, pain, and dyspnea. In other studies, more symptoms were also associated with poorer QoL. ${ }^{14,38,39}$

\section{Conclusions}

A considerable proportion of lung cancer patients are either malnourished or at risk of malnutrition. Malnutrition correlates negatively with QoL and increases symptom severity. Malnutrition is an independent determinant of lower QoL.

\section{Implications for Practice}

Nutritional interventions should be considered as a way to support the overall strategy of cancer treatment. Nutritional assessment should be accompanied by QoL evaluation, so that nutritional interventions can be optimized based on a patient's individual requirements. As nutritional interventions may have a clinically significant impact on QoL, nutritional care should be included in any cancer treatment strategy.

\section{Study Limitations}

The small size of the sample, recruited from a single center, may have impacted the results, due to different approaches to nutritional screening and the instruments used. Another limitation is the heterogeneity of the sample in terms of cancer type, stage, and treatment, as all these factors may have affected results. To obtain a fuller view of the group studied, it would be recommendable to include an evaluation of pain and affective disorders such as anxiety and depression, as all these factors may be significant to QoL.

\section{Disclosure}

The authors report no conflicts of interest for this work.

\section{References}

1. http://epid.coi.waw.pl/krn/n.d.

2. Bray F, Ferlay J, Soerjomataram I. Global cancer statistics 2018: GLOBOCAN estimates of incidence and mortality worldwide for 36 cancers in 185 countries. CA Cancer J Clin. 2018;68(6):394-424. doi:10.3322/caac. 21492 .

3. Jemal A, Siegel R, Xu J, Ward E. Cancer statistics, 2010. CA Cancer J Clin. 2010;60:277-300. doi:10.3322/caac.20073

4. Farbicka P, Nowicki A. Palliative care in patients with lung cancer. Contemp Oncol. 2013;17(3):238-245. doi:10.5114/wo.2013.35033. 
5. Drescher C, Konishi M, Ebner N, Springer J. Loss of muscle mass: current developments in cachexia and sarcopenia focused on biomarkers and treatment. Int $J$ Cardiol. 2016;202:766-772. doi:10.1016/j. ijcard.2015.10.033.

6. Hackshaw AK, Law MR, Wald NJ. The accumulated evidence on lung cancer and environmental tobacco smoke. BMJ 1997;315:980-988. doi:10.1136/bmj.315.7114.980

7. Montazeri A, Milroy R, Hole D, McEwen J, Gillis CR. Anxiety and depression in patients with lung cancer before and after diagnosis: findings from a population in Glasgow, Scotland. J Epidemio Community Health. 1998;52(3):203-204. doi:10.1136/jech.52.3.203.

8. Gupta D, Lis CG, Granick J, Grutsch JF, Vashi PG, Lammersfeld CA. Malnutrition was associated with poor quality of life in colorectal cancer: a retrospective analysis. J Clin Epidemiol. 2006;59 (7):704-709. doi:10.1016/j.jclinepi.2005.08.020.

9. McCabe RM, Grutsch JF, Nutakki SB, Braun DP, Markman M. Can quality of life assessments differentiate heterogeneous cancer patients? PLoS One. 2014;9(6):e99445. doi:10.1371/journal. pone.0099445.

10. Yam PS, Butowski CF, Chitty JL, et al. Impact of canine overweight and obesity on health-related quality of life. Prev Vet Med. 2016;127:64-69. doi:10.1016/j.prevetmed.2016.03.013.

11. Tong $\mathrm{H}$, Isenring $\mathrm{E}$, Yates $\mathrm{P}$. The prevalence of nutrition impact symptoms and their relationship to quality of life and clinical outcomes in medical oncology patients. Support Care Cancer. 2009;17 (1):83-90. doi:10.1007/s00520-008-0472-7.

12. Küçükkatirci S, Sahin H, Soylu M, Çiçek B. Nutritional status and quality of life in lung cancer patients. Studies Ethno-Med. 2017;11 (3):268-277. doi:10.1080/09735070.2017.1305226

13. Caro MMM, Laviano A, Pichard C. Nutritional intervention and quality of life in adult oncology patients. Clin Nutr. 2007;26:289-301. doi:10.1016/j.clnu.2007.01.005

14. Polański J, Jankowska-Polańska B, Uchmanowicz I, Chabowski M, Janczak D, Mazur G. Malnutrition and quality of life in patients with non-small-cell lung cancer. Adv Exp Med Biol. 2017;1021:15-26. doi:10.1007/5584_2017_23.

15. Chabowski M, Polański J, Jankowska-Polańska B, Janczak D, Rosińczuk J. Is nutritional status associated with the level of anxiety, depression and pain in patients with lung cancer? $J$ Thorac Dis. 2018;10(4):2303-2310. doi:10.21037/jtd.2018.03.108

16. Nourissat A, Vasson MP, Merrouche Y, et al. Relationship between nutritional status and quality of life in patients with cancer. Eur $J$ Cancer. 2008;44(9):1238-1242. doi:10.1016/j.ejca.2008.04.006.

17. McCabe MP, Althof SE. A systematic review of the psychosocial outcomes associated with erectile dysfunction: does the impact of erectile dysfunction extend beyond a man's inability to have sex? J Sex Med. 2014;11(2):347-363. doi:10.1111/jsm.12374.

18. Rubenstein LZ, Harker JO, Salvà A, Guigoz Y, Vellas B. Screening for undernutrition in geriatric practice: developing the short-form mini-nutritional assessment (MNA-SF). J Gerontol a Biol Sci Med Sci. 2001;56(6):M366-372. doi:10.1093/gerona/56.6.M366

19. Oken M, Creech R, Tormey D, et al. Toxicity and response criteria of the eastern cooperative oncology group. Am J Clin Oncol. 1982;5:649-655. doi:10.1097/00000421-198212000-00014

20. Polański J, Chabowski M, Jankowska-Polańska B, Janczak D, Rosińczuk J. Histological subtype of lung cancer affects acceptance of illness, severity of pain, and quality of life. J Pain Res. 2018;11:727-733. doi:10.2147/JPR.S155121.

21. Polanski J, Jankowska-Polanska B, Rosinczuk J, Chabowski M, Szymanska-Chabowska A. Quality of life of patients with lung cancer. Onco Targets Ther. 2016;9:1023-1028. doi:10.2147/OTT. $\mathrm{S} 100685$.

22. Jemal A, Siegel R, Ward E, Murray T, Xu J, Thun MJ. Cancer statistics, 2007. CA Cancer J Clin. 2007;57:43-66. doi:10.3322/ canjclin.57.1.43
23. Muscaritoli M, Lucia S, Farcomeni A, et al. Prevalence of malnutrition in patients at first medical oncology visit: the PreMiO study. Oncotarget. 2017;8(45):79884-79896. doi:10.18632/ oncotarget. 20168

24. Pignon J-P, Tribodet H, Scagliotti GV, et al. Lung adjuvant cisplatin evaluation: a pooled analysis by the LACE Collaborative Group. $J$ Clin Oncol off J Am Soc Clin Oncol. 2008;26:3552-3559. doi:10.1200/JCO.2007.13.9030.

25. Mentzer SJ, DeCamp MM, Harpole DH, Sugarbaker DJ. Thoracoscopy and video-assisted thoracic surgery in the treatment of lung cancer. Chest. 1995;107:298S-301S. doi:10.1378/ chest.107.6_Supplement.298S

26. Timmerman R, Paulus R, Galvin J, et al. Stereotactic body radiation therapy for inoperable early stage lung cancer. JAMA. 2010;303:1070-1076. doi:10.1001/jama.2010.261.

27. Bharadwaj S, Ginoya S, Tandon P, et al. Malnutrition: laboratory markers vs nutritional assessment. Gastroenterol Rep. 2016;4 (4):272-280. doi:10.1093/gastro/gow013

28. Kiss N, Isenring E, Gough K, Krishnasamy M. The prevalence of weight loss during (chemo) radiotherapy treatment for lung cancer and associated patient- and treatment-related factors. ClinNutr. 2014;33(6):1074-1080.

29. Gul B, Metintas S, Ak G, et al. The relationship between nutritional status and prognosis in patients with locally advanced and advanced stage lung cancer. Support Care Cancer. 2020. doi:10.1007/s00520020-05856-5.

30. Nurwidya F, Syahruddin E, Yunus F. Pain management in lung cancer. Adv Respir Med. 2016;84:331-336. doi:10.5603/ ARM.2016.0043.

31. Mohan A, Singh P, Kumar S, et al. Effect of change in symptoms, respiratory status, nutritional profile and quality of life on response to treatment for advanced non-small cell lung cancer. Asian Pac $J$ Cancer Prev. 2008;9(4):557-562.

32. Payne C, Larkin PJ, McIlfatrick S, Dunwoody L, Gracey JH. Exercise and nutrition interventions in advanced lung cancer: a systematic review. Curr Oncol Tor Ont. 2013;20:e321-337. doi: $10.3747 /$ co.20.1431.

33. Ovesen L, Hannibal J, Mortensen EL. The interrelationship of weight loss, dietary intake, and quality of life in ambulatory patients with cancer of the lung, breast, and ovary. Nutr Cancer. 1993;19:159-167. doi:10.1080/01635589309514246.

34. Scott HR, McMillan DC, Brown DJF, Forrest LM, McArdle CS, Milroy R. A prospective study of the impact of weight loss and the systemic inflammatory response on quality of life in patients with inoperable non-small cell lung cancer. Lung Cancer Amst Neth. 2003;40:295-299. doi:10.1016/S0169-5002(03)00077-1

35. Zimmermann C, Burman D, Swami N, et al. Determinants of quality of life in patients with advanced cancer. Support Care Cancer. 2011;19(5):621-629. doi:10.1007/s00520-010-0866-1

36. Montazeri A, Milroy R, Hole D, McEwen J, Gillis CR. Quality of life in lung cancer patients: as an important prognostic factor. Lung Cancer. 2001;31(2-3):233-240. doi:10.1016/S0169-5002(00)00179-3

37. Mor V, Allen S, Malin M. The psychosocial impact of cancer on older versus younger patients and their families. Cancer. 1994;74 (7Suppl):2118-2127.

38. Hermann CP, Looney SW. Determinants of quality of life in patients near the end of life: a longitudinal perspective. Oncol Nurs Forum. 2011;38(1):23-31. doi:10.1188/11.ONF.23-31.

39. Henoch I, Bergman B, Gustafsson M, Gaston-Johansson F, Danielson E. The impact of symptoms, coping capacity, and social support on quality of life experience over time in patients with lung cancer. J Pain Symptom Manage. 2007;34(4):370-379. doi:10.1016/j. jpainsymman.2006.12.005 


\section{Publish your work in this journal}

Cancer Management and Research is an international, peer-reviewed open access journal focusing on cancer research and the optimal use of preventative and integrated treatment interventions to achieve improved

The manuscript management system is completely online and includes a very quick and fair peer-review system, which is all easy to use. Visit http://www.dovepress.com/testimonials.php to read real quotes outcomes, enhanced survival and quality of life for the cancer patient. from published authors.

Submit your manuscript here: https://www.dovepress.com/cancer-management-and-research-journal 